\title{
PARTICIPAÇÃO E CIDADANIA NAS SOCIEDADES LATINO- AMERICANAS: EXPERIÊNCIAS DE GOVERNANÇA DEMOCRÁTICA
}

Agatha Justen ${ }^{1}$

Claudio Gurgel ${ }^{2}$

\section{Resumo}

Após as experiências ditatoriais, o tema da democracia tornou-se central em diversos países da América Latina. Mecanismos de democracia participativa passaram a ser instituídos por lei, objetivando gerar novos arranjos institucionais e um novo pacto social. Em alguns países da região, como Bolívia, Equador e Venezuela, os prejuízos causados pelo neoliberalismo radicalizaram o discurso e as mudanças legais. Suas Constituições, inaugurando o que passou a ser chamado de "novo constitucionalismo latino-americano", trouxeram a valorização da cidadania, da participação popular nas decisões públicas e do controle social. Contudo, as experiências de gestão democrática têm apresentado consideráveis e repetitivas dificuldades. Isso nos leva, neste artigo, a refletir sobre a relação entre democracia participativa e/ou cidadania e capitalismo, a partir das contribuições de Domenico Losurdo e Ellen Wood.

Palavras-chave: Democracia; Gestão Democrática; Capitalismo.

\section{PARTICIPATION AND CITIZENSHIP IN LATIN AMERICAN COMPANIES: EXPERIENCES OF DEMOCRATIC GOVERNANCE}

\begin{abstract}
After dictator experiences, democracy has become a central issue in several Latin America countries. Mechanisms of participatory democracy

\footnotetext{
${ }^{1}$ Cientista social, Mestre em Administração (EBAPE-FGV), Mestre em Políticas Públicas (UFRJ) e doutoranda em Administração (EBAPE-FGV). Email: agatha_justen@hotmail.com.

${ }^{2}$ Economista, Mestre em Administração Pública (EBAPE-FGV), Mestre em Ciência Política (UFF), Doutor em Educação (UFF). Professor Associado e vice-coordenador do Programa de PósGraduação em Administração (PPAd-UFF). Email: crmgurgel@hotmail.com.
} 


\section{PARTICIPAÇÃO E CIDADANIA NAS SOCIEDADES LATINO-AMERICANAS: EXPERIÊNCIAS DE GOVERNANÇA DEMOCRÁTICA \\ Agatha Justen | Claudio Gurgel}

have been established by law, in order to generate new institutional arrangements and a new social pact. Some countries of that region, namely Bolivia, Equator and Venezuela, the neoliberalism's damage promoted the radicalization of the speech and legal shifts. The Constitutions, which have introduced the "Latin American new constitutionalism", bring citizenship, popular participation on public decision and social control as important values. However, the democratic management experiences have shown significant and repeated difficulties. It brings us, in this paper, to think about the relationship between participatory democracy and/or citizenship and capitalism, through contributions of Domenico Losurdo and Ellen Wood.

Keywords: Democracy; Democratic Management; Capitalism.

\section{PARTICIPACIÓN Y CIUDADANÍA EN EMPRESAS LATINOAMERICANAS: EXPERIENCIAS DE GOBERNABILIDAD DEMOCRÁTICA}

\section{Resumén}

Después de las experiencias dictatoriales, el tema de la democracia se convirtió en central en diversos países de América Latina. Mecanismos de democracia participativa pasaron a ser definidos por la ley, con el objetivo de generar nuevos arreglos institucionales y un nuevo pacto social. En algunos países de la región, como Bolivia, Ecuador y Venezuela, los perjuicios del neoliberalismo radicalizaron el discurso y los cambios legales. Inaugurando lo que pasó a ser llamado de "nuevo constitucionalismo latinoamericano", sus Constituciones han traído la valoración de la ciudadanía, de la participación popular en las decisiones públicas y de control social. Sin embargo, las experiencias de gestión democráticas han presentado repetitivas dificultades. Eso nos lleva, en ese artículo, a reflexionar sobre la relación entre democracia participativa y/o ciudadanía y capitalismos, a partir de las contribuciones de DomenicoLosurdo y Ellen Wood.

Palabras-clave: Democracia; Gestión Democrática; Capitalismo.

\section{Introdução}

O século $\mathrm{XX}$ foi marcado por experiências relativamente comuns aos países latino-americanos, muitas delas de tal forma traumáticas - como as 


\section{PARTICIPAÇÃO E CIDADANIA NAS SOCIEDADES LATINO-AMERICANAS: EXPERIÊNCIAS DE GOVERNANÇA DEMOCRÁTICA \\ Agatha Justen | Claudio Gurgel}

ditaduras - que promoveram um processo de reflexão e questionamento em relação aos modelos legislativos e administrativos importados. Passouse a introduzir nas constituições o reconhecimento das diversidades culturais, a proteção aos grupos indígenas e, no caso brasileiro, às comunidades quilombolas, o reconhecimento das desigualdades geradas pela escravidão e mecanismos para superá-las, dentre outros.

No âmbito dessas mudanças, uma das mais significativas foi a introdução de mecanismos de participação cidadã em esferas de decisão do Estado. A democracia participativa passou a ser reivindicada a partir da descrença em relação ao sistema representativo clássico. Seja pelos golpes de Estado e pelas longas ditaduras civil-militares, seja pelo patrimonialismo e concepção privatista do espaço e da coisa pública que incorre em corrupção dos representantes, por meio de desvios de verbas públicas. Ou ainda de empresários, por meio da sonegação de impostos, tráfico de influência e troca de favores. Por tudo isso e, ademais, pela incapacidade de atender efetivamente às demandas sociais, as eleições deixaram de ser vistas como realização plena da democracia.

O Brasil foi pioneiro na introdução constitucional de mecanismos de participação direta (Constituição de 1988) e na transformação em leis específicas e criação de espaços descentralizados de gestão de políticas públicas. Atualmente, há constituições mais "modernas" e incisivas na sua dimensão cidadã, como as da Venezuela, da Bolívia e do Equador. Ainda assim, o Brasil é um caso ilustrativo na medida em que possui mais de vinte anos de aplicação destes mecanismos de participação.

São vários os autores que se referem a esses três países como referência de mudança na região. Segundo León (2010),

Venezuela, el Estado Plurinacional de Bolivia y Ecuador han innovado sus Constituciones e inscrito sus propuestas de refundación en ellas, los dos últimos se reconocen incluso como Estados plurinacionales, lo que implica una revolución integral del aparato institucional y una gestión compartida con los distintos pueblos originarios; Venezuela, por su parte, se proyecta desde una nueva visión del espacio federal, pautada por territorialidades que resultan de la consecución de la participación popular protagónica y de sus formas organizativas. [...] Pero todos apuntan, a la vez, a construirse como procesos participativos, que colocan al pueblo como actor y objetivo de las resignificaciones en curso, entre ellas la del propio concepto tradicional de democracia (LEÓN, 2010, p. 5).

É o que observam também Coelho, Cunha Filho e Flores (2010), ao afirmarem que

Esos tres casos [Bolívia, Equador e Venezuela] han sido señalados como los más radicales procesos de transición política en la historia reciente de América Latina y tienen en común el hecho de haber pasado por una amplia renovación institucional que, en mayor o menor medida, cuestiona el modelo clásico de democracia 


\section{PARTICIPAÇÃO E CIDADANIA NAS SOCIEDADES LATINO-AMERICANAS: EXPERIÊNCIAS DE GOVERNANÇA DEMOCRÁTICA \\ Agatha Justen | Claudio Gurgel}

representativa mediante la adopción de nuevas Constituciones (COELHO; CUNHA FILHO; FLORES, 2010, p. 74).

Exatamente esses três países determinaram a construção de um campo de estudo na área do Direito denominado de "Novo Constitucionalismo Latino-Americano". Segundo Vieira (2009, p. 15), essa corrente "tem seu marco inicial na promulgação da Constituição Venezuelana de 1999. Deu origem, também, às atuais constituições do Equador (2008) e da Bolívia (2009)". Esses países, segundo os estudiosos do direito constitucional, foram aqueles que mais avançaram em relação à tradição constitucional clássica europeia. Avançaram porque, mesmo partindo dela, conseguiram expressar os seus próprios marcos histórico-culturais; porque distanciaram-se qualitativamente naquilo que o constitucionalismo europeu não conseguiu avançar, com destaque para a relação EstadoSociedade. Essas Constituições assumem algumas frentes importantes que as diferenciam das outras, dentre elas a que mais nos importa: refundam o conceito de "soberania popular", promovendo a participação direta, já na elaboração e aprovação da própria carta maior, e também no controle e condução da administração pública, com a criação de instituições paralelas de controle baseadas na participação popular (Poder Ciudadano na Venezuela, Control Social na Bolívia e Quinto Poder no Equador).

Portanto, acrescentaram às constituições outros instrumentos institucionalizadores e anunciam como eixo de seus governos a ideia de cidadania, referindo-se, como no caso do Equador, a uma "revolução cidadã". Ao fazerem isso, estão tentando criar um novo conceito de cidadania e de democracia, que vai além dos conceitos clássicos e modernos. Não só superam o conceito aristotélico de cidadania - que exclui grande parte da sociedade, como mulheres, estrangeiros, trabalhadores manuais e escravos -, como o próprio conceito de Marshall, porque reconhecem ao cidadão o direito de construir e reconstruir os três direitos (políticos, civis e sociais).

Não precisa dizer que desconstrói a reconceituação da reforma do Estado liberal, para quem o cidadão é um cliente do Estado, leitura que aliás está aquém de Aristóteles. No que tange à democracia, igualmente avança, porque vai além dos limites parlamentares e representativos (legislativo e executivo) que caracterizam a definição moderna trabalhada por Bentham, Mill, Tocqueville e outros. Indo adiante e profundamente diferenciados, em particular a Bolívia e o Equador, os governos desses países se identificaram com/como povos indígenas que estiveram nas raízes da formação histórica de suas sociedades. Trouxeram, junto a isso e por isso, a concepção do buenvivir cujo significado corrente tem sentido oposto ao projeto desenvolvimentista capitalista. É quando se contrapõe um outro objetivo ao objetivo corrente de elevar o produto bruto, ainda que nos marcos do modo de produção capitalista. Nega-se a perspectiva e o plano consumista conhecidos e globalizados. Trata-se de buscar a 


\section{PARTICIPAÇÃO E CIDADANIA NAS SOCIEDADES LATINO-AMERICANAS: EXPERIÊNCIAS DE GOVERNANÇA DEMOCRÁTICA \\ Agatha Justen | Claudio Gurgel}

felicidade, na harmonia entre o homem e a natureza, tentando-se passar ao largo do consumismo e da mercantilização da vida.

O buenvivir ou vivirbien é uma expressão de origem indígena ("sumakkawsay", em quíchua; "suma qamaña", em aymará; e "tekokavi”, em guarani) que significa viver bem, dignamente, em harmonia com a natureza. Está presente especialmente nas constituições equatoriana e boliviana e, em termos de projeto político, busca integrar a população tendo em vista o reconhecimento e o respeito às diversidades, uma estratégia de desenvolvimento voltada para o cidadão em detrimento do mercado e onde a sociedade é soberana e não o Estado (LARREA, 2009; LEÓN, 2010; ARKONABA, 2012). Segundo o Plan Nacional por el Buen Vivir, que estabelece políticas públicas para o período 2013-2017, no Equador, sãodesenvolvidas seis dimensões básicas, dentreelas a participação social ("el cambio social debe llevarse simultáneamente con una creciente participación ciudadana en las decisiones relevantes para la celectividad y la profundización de la democracia" (ECUADOR, 2013, p. 29).

São essas as ideias principais que estão presentes nos textos constitucionais, inaugurando um novo marco conceitual.

Resta saber, entretanto, se, na prática da lei, esses novos conceitos estão se tornando efetivos.

No Brasil, Labra (2006, 210/212), em estudo sobre os Conselhos de Saúde, chega a conclusões preocupantes: (1) de modo geral, os Conselhos não utilizam meios de divulgação de suas atividades (revistas, páginas eletrônicas, etc), o que faz a população, via de regra, desconhecê-los; (2) a adesão pela comunidade é baixa devido ao desconhecimento da estrutura dos Conselhos, de seus objetivos e de sua utilidade. Isso se reflete no baixo envolvimento nas eleições para conselheiros representantes dos usuários; (3) Por outro lado, são muito valorizados por quem os frequenta. Porém, é entendido como um espaço de reivindicações específicas e denúncias pontuais. "A maior parte do tempo de cada reunião mensal é gasta na discussão de assuntos internos, sendo raros os debates de temas substantivos" (LABRA, 2006, p. 13); (4) Há muitas reclamações quanto à postura do secretário de saúde, apontada como autoritária, desrespeitosa e irresponsável. Nas palavras da autora,

Reclama-se que não discutem o orçamento nem prestam contas da sua execução; não acatam as resoluções do colegiado; definem de antemão ou manipulam a pauta de discussão e as deliberações; impõem decisões mediante um discurso tecnocrático; esquivam discussões de teor político; cooptam conselheiros ou lideranças comunitárias com artifícios clientelistas; preenchem o tempo com assuntos internos da gestão ou das corporações profissionais, tornando asreuniões meramente informativas de assuntos alheios aos interesses da comunidade; não controlam os prestadores privados e incluso 


\section{PARTICIPAÇÃO E CIDADANIA NAS SOCIEDADES LATINO-AMERICANAS: EXPERIÊNCIAS DE GOVERNANÇA DEMOCRÁTICA \\ Agatha Justen | Claudio Gurgel}

incentivam a expansão destes mediante a terceirização de serviços, sem qualquer consulta ao CS (LABRA, 2006, p. 13).

Na Bolívia, a partir do minucioso estudo de Lanza (2013) sobre participação cidadã no município de La Paz, conseguimos ter uma visão geral do modo como está esse processo na atualidade. Através do acompanhamento de reuniões e entrevistas com representantes de todos os setores envolvidos com participação cidadã, planejamento municipal e as autoridades públicas, a autora destaca os seguintes pontos:

1. Reconhecimento por parte dos membros do Comitê de Vigilância (CV) das dificuldades de conhecimento técnico para realizar o controle.

2. Baixa participação da comunidade tanto nos processos eleitorais para escolha de seus representantes que farão frente ao poder público, quanto no dia a dia das reuniões das Juntas Vicinais. É o que se verifica na fala de um membro de CV: "es escasa la participación, raros son las Juntas Vecinales que cuando se los convoca asisten en su plenitud, muy raro porque son gente ocupada, trabajan en la ciudad sal en a las 7 de la mañana, regresan 8, 9 de la noche, entonces es muy difícil, sin embargo, cuando hay una convocatoria que es de interés de la zona, asisten, siempre y cuando la convocatoria sea realizada con tiempo, asisten" (LANZA, 2013, p. 177).

3. São poucos ou nulos os canais de comunicação dos representantes com a comunidade,

4. Sobreposição de papéis e funções de diferentes instâncias de representação cidadã,

5. Pouca disposição por parte do governo municipal em compartilhar os projetos e planejamento municipal com os representantes da sociedade. Como afirma Lanza, "el GMLP [Governo Municipal de La Paz] se limita a la socialización de su propuesta -previamente definida por los funcionarios - y que si bien se anotan las sugerencias emitidas por las $J V$, no son efectivamente incluidas" (LANZA, 2013, p.184).

No Equador, a despeito de se encontrar um clima efetivamente estimulante, criado pelo ambiente de transformação e pela própria Carta Magna e suas leis decorrentes, o fato é que logo no artigo 2 da Ley Orgânica se coloca uma restrição desconcertante.

Tratando do Âmbito da lei, o artigo informa que "la presente Ley tiene aplicación obligatória para todas las personas enel território ecuatoriano", no entanto, em se tratando de empresas privadas, o âmbito da lei está cingido a "(instituiciones) privadasque manejenfondos públicos ou desarrollen atividades de interés público" (ECUADOR, 2010, p. 6).

Vale lembrar que no Brasil, a tentativa de instituir a participação da sociedade, levada a efeito pelo governo central, com a proposta do Decreto 8.243/2013, que criaria a Política Nacional de Participação Social, também 


\section{PARTICIPAÇÃO E CIDADANIA NAS SOCIEDADES LATINO-AMERICANAS: EXPERIÊNCIAS DE GOVERNANÇA DEMOCRÁTICA \\ Agatha Justen | Claudio Gurgel}

limitava a ação pública aos espaços da administração pública estatal e nãoestatal.

Ainda tratando da Ley Orgânica, vamos reencontrar a mesmarestrição de âmbito no artigo 30, quando se lê que "Se reconece todas las formas de organización de la sociedade [...] que incidan en las decisiones y politicas públicas $y$ en control social de todos los niveles del gobierno, asi como de las entidades públicas y de las privadas que presten servícios públicos (ECUADOR, 2010, p. 39-40).

Significa dizer que milhões de cidadãos que se encontram no âmbito das empresas privadas que não aquelas que "prestenservicios públicos" estão excluídos por lei da participação que a Constituição, em princípio, lhes tinha outorgado.

Esta autolimitação do Estado, cujos poderes são capazes de intervir na vida privada, em nome da segurança pública, por exemplo, é uma demonstração da soberania do mercado, mesmo em ambiente transformador, que anuncia uma revolución ciudadana.

Sem com isto pretender desmerecer os valores que se encontram nas iniciativas constitucionais e nos dispositivos legais ordinários que procuram estimular a participação e o controle social, é inevitável que esta definição de âmbito, uma definição limitadora,seja um sinal importante da relação entre o Estado e o mercado, no Equador.

Esta situação igualmente sinaliza para algo fora do lugar, considerando-se o discurso oficial, na relação do Estado equatoriano com o mercado.

Ainda que ilustrativamente, podemos trazer um dado prático, que é exposto por Arturo Villavicencio, em seu texto? ¿Hacia dónde va el proyecto universitario de la revolución ciudadano? (VILLAVICENCIO, 2013).

Villavicencio foi membro do PanelIntergubernamentaldel Cambio de Clima (IPPCC), ganhador do Prêmio Nobel em 2007, e tem o reconhecimento nacional e internacional pelos seus muitos trabalhos realizados no campo da energia, ambiente e desenvolvimento sustentável. Hoje é professor da Universidade Andina Simón Bolivar e seu texto é um debate sobre a política pública de educação superior.

Neste aspecto Villavicencio critica o governo, dizendo que "laspoliticas no pueden continuar siendodictadas por autoridades legitimas atuando ilegitimamente (porque exceden sus atribuicionesinstitucionales), referindo-se a "discrecionalidad y arbitrariedade de lasdecisiones" (VILLAVICENCIO, 2013, p. 53).

Significativamente, Villavicencio associa esta conduta ao que chama de capitalismo acadêmico, usando a expressão de Slaughter y Roades, autores de Academic capitalism and the new economy. Em suas palavras, "la vision funcional y empresarial de la universidad, productora de recursos humanos y conocimientos directamente relevantes para la esfera productiva y el mercado, está interrompendo, cada vez com más fuerza, la esfera académica" (VILLAVICENCIO, 2013, p. 31). 


\section{PARTICIPAÇÃO E CIDADANIA NAS SOCIEDADES LATINO-AMERICANAS: EXPERIÊNCIAS DE GOVERNANÇA DEMOCRÁTICA \\ Agatha Justen | Claudio Gurgel}

O que faz com que os generosos esforços para construção constitucional e infraconstitucional da democracia popular encontre sua negação na prática, no concreto, no seu funcionamento real?

É sobre isto que trazemos Losurdo e Wood para nos ajudar a entender este fenômeno frustrante da experiência latino-americana.

\section{Democracia e Capitalismo: Incompatibilidades Reais}

Domenico Losurdo, ao abordar o pensamento de Tocqueville, enfatiza a dicotomia igualdade/liberdade com que o diplomata francês reflete sobre a democracia. A relação entre igualdade e liberdade, vista aliás como valores contraditórios, possui grande relevância, dado que expressa não apenas a visão de um pensador, mas a essência do pensamento liberal sobre o modelo de democracia. Fundamentalmente, o bem supremo é a liberdade; a igualdade, à medida que exerce peso negativo sobre a liberdade, deve ser ela própria controlada. Somos levados por Tocqueville a concluir que a democracia, para o bem do sistema, não pode se abrir até o ponto em que essas massas descontroladas sejam as responsáveis por decidir os rumos de uma nação. Seria a "tirania da maioria", tão temida pelos liberais e, por suposto, igualmente por Tocqueville, que em certo momento de suas reflexões diz: "acho que a onipotência da maioria é um perigo tão grande para as repúblicas americanas que o recurso perigoso empregado para limitá-la me parece ainda benéfico" (LOSURDO, 2004, p. 171). Até onde pode levar este "recurso perigoso"?

Em Tocqueville, esse é um raciocínio que se aprofunda nos discursos políticos, na sua trajetória parlamentar, em obras posteriores à Democracia na América e em cartas pessoais. São esses documentos que Losurdo minuciosamente analisa em Democracia ou Bonapartismo (2004). Ele encontra inúmeras passagens bastante ilustrativas, como por exemplo, quando o pensador francês fala sobre as lutas travadas na França de seu tempo contra a discriminação censitária:

\footnotetext{
Tocqueville escreveu tratar-se de um movimento que cometia a imprudência de apelar ao "povo" e que ele temia pudesse escapar, como depois efetivamente aconteceu, da direção e do controle da "classe média", isto é, da burguesia" ou na polêmica "contra a agitação dos banquetes, declara: "Não se deve cortejar o povo e não se deve conferir-lhe, pródiga e temerariamente, mais direitos políticos do que aqueles que é capaz de exercer (LOSURDO, 2004, p. 21).
}

Em Democracia na América, Tocqueville trata do sistema de representação nos EUA: “a câmara dos representantes é nomeada pelo povo; o senado, pelos legisladores de cada Estado. Uma é o produto da eleição direta, a outra da eleição em dois graus" (TOCQUEVILLE, 2005, p. 


\section{PARTICIPAÇÃO E CIDADANIA NAS SOCIEDADES LATINO-AMERICANAS: EXPERIÊNCIAS DE GOVERNANÇA DEMOCRÁTICA \\ Agatha Justen | Claudio Gurgel}

137). Mais à frente, após a ressalva de que "há certas leis cuja natureza é democrática mas que conseguem corrigir em parte esses instintos perigosos da democracia", ele expressa suas impressões sobre as duas câmaras:

Quando você entra na sala dos representantes em Washington, sente-se chocado com o aspecto vulgar dessa grande assembléia. Seu olhar busca, não raro em vão, em seu interior um homem célebre. Quase todos seus membros são personagens obscuros, cujo nome não fornece nenhuma imagem ao pensamento. São, na maioria, advogados de província, comerciantes ou mesmo homens pertencentes às últimas classes. Num país em que a instrução é quase universalmente difundida, diz-se que os representantes do povo nem sempre sabem escrever corretamente.A dois passos dali abre-se a sala do senado, cujo estreito recinto encerra uma grande parte das celebridades da América. Mal percebemos lá um só homem que não evoque a idéia de uma ilustração recente. São eloqüentes advogados, generais distintos, hábeis magistrados ou homens de Estado conhecidos. Todas as palavras que escapam dessa assembléia fariam honra aos maiores debates parlamentares da Europa.Donde vem esse contraste esquisito? Por que a elite da nação se encontra nesta sala e não na outra? Por que a primeira assembléia reúne tantos elementos vulgares, ao passo que a segunda parece ter o monopólio dos talentos e das luzes? Ambas porém emanam do povo, ambas são produto do sufrágio universal e nenhuma voz, até aqui, já se elevou na América para sustentar que o senado fosse inimigo dos interesses populares.Donde vem pois tão enorme diferença? A meu ver um só fato a explica: a eleição que produz a câmara dos representantes é direta; aquela de que emana o senado é submetida a dois graus. A universalidade dos cidadãos nomeia a legislatura de cada Estado, e a constituição federal, transformando por sua vez cada uma dessas legislaturas estaduais em corpo eleitoral, aí buscaos membros do senado. Os senadores exprimem portanto, muito embora indiretamente, o resultado do voto universal (TOCQUEVILLE, 2005, p. 235).

Seria essa a característica do sistema estadunidense mais inovadora, aquela capaz de fazer com que

os homens assim eleitos representem pois, sempre exatamente, a maioria da nação que governa; mas representem tão-somente os pensamentos elevados que lá circulam, os instintos generosos que a animam, e não as pequenas paixões que muitas vezes agitam-na e os vícios que a desonram(TOCQUEVILLE, 2005, p. 235-236).

Dessa forma, os EUA conseguem "de modo ainda mais eficaz, proteger os organismos representativos da influência, ou da excessiva 


\section{PARTICIPAÇÃO E CIDADANIA NAS SOCIEDADES LATINO-AMERICANAS: EXPERIÊNCIAS DE GOVERNANÇA DEMOCRÁTICA \\ Agatha Justen | Claudio Gurgel}

influência, das massas populares" sem recorrer "a discriminações patentes e muitas vezes percebidas como odiosas", considera Tocqueville (LOSURDO, 2004, p. 18). É isso que faz com que os EUA gozem de uma "invejável estabilidade política", a despeito da "ampla extensão do sufrágio", conclui o pensador francês (LOSURDO, 2004, p. 18).

Estas condições colocadas pelo capitalismo se expressam na democracia liberal e, por suposto, nas formas mais radicais de democracia, mantidas as condições capitalistas estruturais.

A questão é: que democracia é essa? Quais elementos passaram a defini-la? Para responder a tais indagações é necessário voltar ao conceito clássico aristotélico, e analisar as modificações sofridas à medida que os processos sociais foram avançando. Ellen Wood (2011) faz essa análise em Democracia contra Capitalismo. O ponto central de separação entre o modelo grego e o modelo "moderno" é a representação versus participação direta. Aristóteles via com muita restrição qualquer tipo de representação. A eleição era concebida como constitutiva de um sistema oligárquico, "porque tendia a favorecer os notáveis, os ricos e bem-nascidos, que talvez fossem menos simpáticos à democracia" (WOOD, 2011, p. 187).

Esse modelo encontrava sérios limites e, somados à realidade socioeconômica geral, estimulava a revolta popular. Era, de fato, uma situação contraditória, dado que a manutenção daquela ordem partiada exclusão das massas do núcleo de poder e, ao mesmo tempo, tal exclusão motivava as massas a subverterem a ordem. Esse trade-off encontrou uma faceta dramática nos EUA. Como relata Wood, embora os antidemocratas tenham saído vitoriosos na disputa pela definição da nova república, a experiência colonial e do processo que culminou na revolução criou uma população politicamente ativa e com grande impulso para a democracia de massa (WOOD, 2011, p. 187). Os federalistas, por isso, "tinham pela frente uma tarefa sem precedentes, a de preservar o que fosse possível da divisão entre massa e elite no contexto de franquias crescentemente democráticas e de um corpo de cidadãos cada vez mais ativo" (WOOD, 2011, p. 185). Em outras palavras, seria necessário encontrar uma maneira de manter o domínio da minoria proprietária com o apoio popular. Foi assim que os federalistas redefiniram a democracia. Encontraram no modelo representativo a fórmula para manter o status quo e disfarçar as ambiguidades inerentes a sua forma de dominação. Como destaca Wood (2005, p. 187),

\footnotetext{
já nos acostumamos tanto à fórmula "democracia representativa" que tendemos a esquecer a novidade da ideia americana. Pelo menos em sua forma federalista, ela significou que algo até então percebido como antítese de autogoverno democrático passava a ser não apenas compatível com a democracia, mas também um de seus componentes: não o exercício do poder político, mas renúncia a este poder, sua transferência a outros, sua alienação.
} 


\title{
PARTICIPAÇÃO E CIDADANIA NAS SOCIEDADES LATINO-AMERICANAS: EXPERIÊNCIAS DE GOVERNANÇA DEMOCRÁTICA \\ Agatha Justen | Claudio Gurgel
}

O sistema representativo não foi criado pelos federalistas. Contudo, essa definição de democracia, tal como concebida nos EUA, tornou-se referencial na democracia moderna, que é a "identificação desta com a alienação do poder" (WOOD, 2005, p. 188). Pela análise das reflexões dos "pais fundadores" desse sistema, Wood é categórica ao afirmar que eles

\begin{abstract}
não somente concebiam a representação como uma forma de distanciar o povo da política, mas advogavam-na pela mesma razão que justificava as suspeitas dos atenienses contra as eleições: por ela favorecer as classes proprietárias. A "democracia representativa", tal como uma das misturas de Aristóteles, é a democracia civilizada com um toque de oligarquia (WOOD, 2005, p. 188).
\end{abstract}

Losurdo, em A Contra-História do Liberalismo, já questiona "o que é liberalismo?". Poderia ser uma pergunta banal se a resposta fosse aquela conhecida pelo senso comum e proferida pelos seus defensores: defesa intransigente da liberdade do indivíduo, sendo este o centro de suas preocupações. A dificuldade aparece quando se leva em conta que grande parte dos expoentes do liberalismo, desde Locke, na mesma medida em que exaltavam a liberdade do indivíduo a todo custo contra a tirania da ação do Estado, defendiam a existência e a reprodução da escravidão. O próprio Locke, ao mesmo tempo em que "atacava com palavras de fogo a "escravidão" política que a monarquia absoluta queria impor" (LOSURDO, 2006, p. 15), "procurava justificar a escravidão absoluta e perpétua" (Ibid.) e, ademais, era acionista da Royal AfricanCompany, empresa inglesa de tráfico de escravos. John Stuart Mill, embora se colocasse contra o que ele chamava de "autodeterminados" liberais estadunidenses que aceitavam a secessão escravista, afirmava que esta não seria tão ruim se praticada, por exemplo, na África, lugar atrasado, de “tribos selvagens" (LOSURDO, 2006, p. 19).

O pensador italiano chega, então ao questionamento: pode ser considerado liberal quem defende a escravidão?

Do ponto de vista prático, grandes potências que serviram de esteio ao pensamento liberal tiveram a escravidão e o comércio de escravos como eixo de sustentação de seu desenvolvimento. Isso se aplica, por exemplo, à Inglaterra e à Holanda.

A pergunta de Losurdo pode ser respondida com um convicto "sim". Os liberais não tiveram nenhum pudor em defender voto censitário e voto plural, como expõe o próprio Losurdo, tratando de Stewart Mill. Na contemporaneidade, não houve qualquer pudor por parte de Friedman e seus auxiliares para levar adiante no Chile de Pinochet a experiência neoliberal latino-americana. 


\section{PARTICIPAÇÃO E CIDADANIA NAS SOCIEDADES LATINO-AMERICANAS: EXPERIÊNCIAS DE GOVERNANÇA DEMOCRÁTICA \\ Agatha Justen | Claudio Gurgel}

Podemos dizer, finalmente, que toda a tradição do liberalismo e do capitalismo não converge para a democracia, nem para suas formas mais avançadas que se pretendem em parte da América Latina.

\section{Conclusão}

Há avanços importantes que ocorreram a partir dos anos 2000 em alguns países, em especial no que tange à ordem jurídica que trata do poder. O neoconstitucionalismo latino americano é de fato uma conquista. Está certo Lanza, quandodiz que "son evidentes e innegables los avances en la convocatoria, el impacto en la gestión municipal, y el acercamiento entre gobierno municipal y ciudadanos" (LANZA, 2013, p. 244). Isso se verificou, por exemplo, na formulação do Plano de Desenvolvimento Municipal (PDM) 2007-2011, na Bolívia, que se utilizou de uma metodologia expansiva da lógica territorial participativa, implementou múltiplos espaços de diagnóstico e reflexão e incluiu novos atores.

No entanto, não é possível deixar de considerar que ainda há inúmeros problemas, muitos dos quais já eram conhecidos no período anterior, que inviabilizam a concretização da geração de valor público e principalmente da consolidação de um novo paradigma decisório.

Limitações materiais, que colocam os organismos da democracia participativa dependente do poder do Estado, até mesmo em relação às instalações onde funcionar; informações precárias ou até mesmo desinformações, que restringem a particpação, em especial daqueles que frequentemente são excluídos das decisões; falta de regularidade nos eventos decisórios; caráter meramente consultivo dos foruns de controle e participação sociais; distância intelectual e informacional entre os participantes; baixa representatividade dos participantes, muitas vezes investidos pelo próprio Estado da função de representantes; descolamento dos representantes em relação aos seus representados; burocratização dos processos; centralização e autoritarismos dos agentes do Estado; existência de espaços paralelos ou desconhecidos, onde de fato se dão as decisões e operam os lobbystas e outros interessados, cujos elos com o poder lhes facilita a obtenção de vantagens.

Esta lista de adversidades pode crescer, mas, independentemente do seu tamanho, se manifesta nas diferentes experiências que trouxemos a este debate.

A questão que se coloca à nossa reflexão é: o quanto destes problemas são dificuldades trazidas por uma tradição de centralização e autoritarismo, que não se encontra na natureza do sistema, mas em sua imaturidade. $\mathrm{Ou}$, ao contrário: tudo isto é o resultado inevitável de uma estrutura do Estado e da classe dominante que não permite a evolução das formas de democracia que compartilham o poder em plano de igualdade.

A se considerar como parte integrante do sistema capitalista a divisão de classes e, em especial, a oposição antagônica de classes, não seria 


\section{PARTICIPAÇÃO E CIDADANIA NAS SOCIEDADES LATINO-AMERICANAS: EXPERIÊNCIAS DE GOVERNANÇA DEMOCRÁTICA \\ Agatha Justen | Claudio Gurgel}

estranho dizer que a democracia, como concebida na sua radicalidade, dificilmente poderia se desenvolver satisfatoriamente.

Supor que os interesses da classe dominada encontrariam espaço para se afirmar diante dos interesses da classe dominante parece ingênuo, ainda que se possam considerar as situações contraditórias e as variadas situações especiais criadas pelas relações complexas interclasses, fora e dentro do Estado.

O processo democrático ampliado e próximo da democracia direta implica a predominância da maioria nas decisões, a mesma maioria marcada pelas paixões, que tanta preocupação trazia a Tocqueville. É esta maioria que se compõe das grandes massas excluídas, não só dos espaços de decisão, mas também da partilha da riqueza produzida.

É esta partilha da riqueza que está em jogo, quando se fala de participação popular nos processos de decisão da esfera pública. Mais ainda quando se pode imaginar a colocação em pauta, nos foruns de decisão pública, de questões que dizem respeito a direitos sociais, direitos trabalhistas e de propriedade.

Significa dizer que estamos conjecturando que a democracia participativa, seus mecanismos de funcionamento e sua radicalidade parecem não se compatilizar com o modo de produção capitalista, fundado na expectativa do lucro a partir da exploração do trabalho.

Não cabe a conclusão simplista de que esta condição estrutural invalida por inteiro os esforços que estão sendo conduzidos nesses países latinoamericanos para ampliar a democracia e interessar os populares nos processos decisórios públicos. Não. Estes esforços têm papel e têm importância.

Mas os limites disto nos indicam suficientemente que os problemas diagnosticados não são acidentais. Exigem a mesma radicalidade em reformas que mudem as relações sociais no mercado e na sociedade. Neste sentido, não é frase de efeito dizer que a persistência neste caminho é que fará andar a sociedade - cabendo estar alertas para perceber se estamos andando para frente ou se estamos dando um passo adiante e dois atrás.

\section{Referências}

ARKONABA, Katu. Transiciones hacia el Vivir Bien: o la construcción de un nuevo proyecto político en el Estado Plurinacional de Bolivia. La Paz: Ministérios de Culturas, 2012. Disponível em http://www.rebelion.org/docs/161862.pdf . Acesso em: 19 ago.2014.

COELHO, André Luiz; CUNHA FILHO, Clayton Mendonça; FLORES, Fidel Pérez. Participación ampliada y reforma del Estado: mecanismos constitucionales de democracia participativa en Bolivia, Ecuador y Venezuela. OSAL (Buenos Aires: CLACSO) Año XI, n. 27, abril, 2010. 
ECUADOR. Ley Organica de Participaçión Ciudadano. Quito: Registro Oficial, 2010.

ECUADOR. Plan Nacional para el Buen Vivir 2013-2017. Quito: Secretaria Nacional de Planificación y Desarrollo, 2013.

LABRA, Maria Eliana. Conselhos de Saúde: visões "macro" e "micro". Civitas - Revista de Ciências Sociais, v. 6, n. 1, jan.-jun., 2006.

LANZA, Jessica Doris. Generando Valor Público desde la Participación Ciudadana en los Municipios Bolivianos: la transformación de la Gestión el Municipio de La Paz. 2013. Tese (Doutorado em Política Pública EGAP), 2013.

LARREA, Ana María. La Disputa de Sentidos por el Buen Vivir como Proceso Contra hegemónico. Quito, 2009. Disponível em http:/ / www.redeplan.info/documents/10157/19677/ AnaMariaLarrea.p df. Acesso em: 19 ago.2014.

LEÓN, Irene (coord.). SumakKawsay / Buen Vivir y Cambios Civilizatorios. Quito: FEDAEPS, 2010.

LOSURDO, Domenico. Democracia ou Bonapartismo?Rio de Janeiro: Editora UFRJ; São Paulo: Editora Unesp, 2004.

Contra-história do liberalismo. São Paulo: Ideias \& Letras, 2006.

VILLAVICENCIO, Arturo. ? ¿Hacia dónde va el proyecto universitario de la revolución ciudadano? Quito: 13 Ediciones, 2013.

WOOD, Ellen. Democracia contra capitalismo. São Paulo: Boitempo, 2011. 